\title{
ZNO-Ag/PS and ZnO/PS Films for Photocatalytic Degradation of Methylene Blue
}

\author{
Hassan Khuder Naji ${ }^{1}$, Amjed Mirza Oda ${ }^{1{ }^{*}}$, Wesam Abdulaljeleel ${ }^{2}$, \\ Hussein Abdilkadhim ${ }^{2}$, and Rawaa Hefdhi' \\ ${ }^{1}$ Science Department, College of Basic Education, University of Babylon, Babylon 51002, Iraq \\ ${ }^{2}$ Department of Chemistry, College of Sciences, University of Babylon, Babylon 51002, Iraq
}

* Corresponding author:

tel: $+964-7812475243$

email:almajid1981@yahoo.com

Received: November 27, 2018

Accepted: March 27, 2019

DOI: $10.22146 /$ ijc. 41347

\begin{abstract}
Two films of $\mathrm{ZnO}-\mathrm{Ag} /$ polystyrene $(\mathrm{ZnO}-\mathrm{Ag} / \mathrm{PS})$ and $\mathrm{ZnO} /$ polystyrene $(\mathrm{ZnO} / \mathrm{PS})$ have been prepared and the photodegradation ability of stabilized catalysts was evaluated for methylene blue $(\mathrm{MB})$ degradation. The efficiency of $\mathrm{ZnO}$ improved against recombination of electron-hole pair by modification of catalyst surface with $\mathrm{Ag}$ photodeposition to be more resistant towards photocorrosion. ZnO-Ag catalyst was characterized by SEM and EDS analysis to show high roughness of this catalyst and $\mathrm{Ag}$ deposited on the surface was $2 \%$ (molar ratio). $\mathrm{ZnO}-\mathrm{Ag} / \mathrm{PS}$ and $\mathrm{ZnO} / \mathrm{PS}$ composites were made as films and were then analyzed by FTIR spectra that showed the interaction of $\mathrm{ZnO}$ and $\mathrm{ZnO}-\mathrm{Ag}$ with polystyrene appeared in the range of 400-620 $\mathrm{cm}^{-1}, X R D$ pattern indicated the presence of $\mathrm{Ag}$ nanoparticles on the surface of $\mathrm{ZnO}$ and $\mathrm{ZnO} / P S$ film has maximum absorbance at $376 \mathrm{~nm}$ in UV-VIS spectra. This value shifted to $380 \mathrm{~nm}$ because of the photodeposition. The photocatalytic reaction was depicted using $M B$ in the $U V$ irradiation action of stacked films in $\mathrm{MB}$ solution. The result showed that both $\mathrm{ZnO}$ $\mathrm{Ag} / \mathrm{PS}$ and $\mathrm{ZnO} / \mathrm{PS}$ films gave efficiency to remove $\mathrm{MB}$ by $97 \%$ and $70 \%$, respectively. The reusability test of the films showed that $\mathrm{ZnO}-\mathrm{Ag} / \mathrm{PS}$ was more resistant than $\mathrm{ZnO} / \mathrm{PS}$. The presence of $\mathrm{Ag}$ also increased the efficiency in photodegradation and resistance against photocorrosion.
\end{abstract}

Keywords: photocatalysis; photodeposition; $\mathrm{ZnO}$-Ag; methylene blue

\section{- INTRODUCTION}

Photocatalysis techniques are new eco-friendly methods for environmental treatments to decontamination dyes in the wastewater. Metal oxide semiconductors as heterogeneous photocatalyst are an important material that utilized by many applications in industry and many technological processes like environmental and biomedical applications [1-2]. One of the serious problems in wastewater is contamination with an organic and inorganic dye that discharged to aquatic habit, which will add high risk to living organisms leading to pollution crises. Dyes are powerful coloring agent in the textile and leather industry.

On the other hand, these dyes are nonbiodegradable when expelled to the ecosystem and resisted degradation so that it will cause health problems according to carcinogenic nature. Also, their presence made problem in an aquatic system like low illumination reaching the bottom and low oxygen demand [3-4]. Dyes can be removed using photocatalysis reaction in the presence of titanium dioxide $\left(\mathrm{TiO}_{2}\right)$ and zinc oxide $(\mathrm{ZnO})$, and these catalysts can harvest light energy for photodegradation and significantly enhance the rate of degradation [5].

Semiconductor catalyst such as $\mathrm{ZnO}$, when illuminated with photons forms in the valence band (VB) a positive hole $\left(\mathrm{h}^{+}\right)$and the conduction band (CB) an electron $\left(\mathrm{e}^{-}\right)$. The positive hole oxidized by hydroxyl ions to produce hydroxyl radicals $\left(\mathrm{OH}^{*}\right)$ and causing degradation of organic contaminants directly or indirectly. In the conduction band, the electron is consumed by adsorbed oxygen and forms oxygen superoxide. These species enhance the rate of 
degradation by destroying the chemical structure through several steps of oxidation, reaching mineralization the dyes converting into $\mathrm{CO}_{2}$ and $\mathrm{H}_{2} \mathrm{O}$ [6-7].

$\mathrm{TiO}_{2}$ is most widely used in photocatalysis to decontamination of dyes, but $\mathrm{ZnO}$ also has similar activity to be useful like $\mathrm{TiO}_{2}$ where its band gap energy is $3.2 \mathrm{eV}$. $\mathrm{ZnO}$ has a relatively lower cost of production and ease in the separation of electrons and holes charges. Thus $\mathrm{ZnO}$ can be used as an alternative catalyst instead of $\mathrm{TiO}_{2}$ [810]. However, the capability of $\mathrm{ZnO}$ in photodegradation opposite its poor chemical stability under photocatalytic reaction [11] as it undergoes corrosion by self-oxidation under UV irradiation, leading to the loss of the photocatalytic activity. Thus, it needs to improve the photostability by incorporation into various composites like $\mathrm{TiO}_{2}$ or by deposition of noble metals like $\mathrm{Ag}$ on the surface $[5,12]$.

Efficient photocatalytic degradation of organic pollutants was reported by depositing $\mathrm{TiO}_{2}$ ultrathin layer on $\mathrm{Ag}$ - $\mathrm{ZnO}$ nanorods, where the addition of $\mathrm{Ag}$ work as a sink for electron collector and prevent charges recombination. The $\mathrm{TiO}_{2}$ layer increases the stability of photocatalyst against photo-corrosion under UV irradiation [12]. Several studies have designated that the photocatalytic rate increases with catalyst loading with metal, but at high concentrations of metal load will lose its efficiency, because of light scattering and screening effects happened [13]. Also, photodegradation is more efficient in case of increasing the lifetime of electron-hole separation and retarding recombination. According to this method, incorporation of species that accept electrons at conduction band of the photocatalyst, like transition metal ions or oxides increases the activity in degradation comparing to bare semiconductors. The consuming of a photo-excited hole by photooxidation species are expected could reduce the recombination process and make it highly efficient $[5,12,14]$. Usually, defect in photocatalyst by doping makes shifting in band gap to less value; therefore, the addition of dopants decrease the band gap causing surface modification by the new site and lifetime charges carriers' recombination is retarded and increase the photocatalyst ability in the photodegradation process [15-16].
In many previous reports, the photocatalytic reaction usually constructed according to the common protocol, where the photocatalyst is used as a powder and added to the dye solution with stirring to get a slurry, then illuminated with proper source of light to initiate the photocatalytic reaction. This protocol is limited to be used in industrial treatment units, because the recovery of catalyst and takes more times for continuing the treatment units work or expelled the catalyst to the environment, leading another problem. In our previous study, the photocatalyst is stabilized on a surface like cotton fiber by impregnation of in $\mathrm{ZnO}$ and $\mathrm{ZnO}-\mathrm{Ag}$ and used for photodegradation of safranin $\mathrm{O}$ dye [17-18]. In addition, silver incorporation in $\mathrm{TiO}_{2}$ and a polystyrene matrix was made to remove dye from wastewater as a floating photocatalyst [19]. Zinc oxide nanoparticles were also fixed on glass plates as a photocatalyst to remove Acid Red 88 dye in aqueous solution [20]. This strategic way reported that mixing the photocatalyst with polymer matrix gives a new technique in water purification with characteristic features like good photocatalytic activity, low cost in consuming of the catalyst and no need to recover the catalyst after water treatment [21].

Thus in this study, the action of $\mathrm{ZnO}$ doped $\mathrm{Ag}$ and comparison of photodegradation of methylene blue solution were demonstrated, where MB is likely used as an example to evaluate the photodegradation efficiency [22]. In the presence of $\mathrm{ZnO} / \mathrm{PS}$ and $\mathrm{ZnO}-\mathrm{Ag} / \mathrm{PS}$, both of them are stabilized in the polystyrene matrix controlling the photocatalyst to be not expelled to the environment. Some analysis like UV Vis, FTIR, XRD, SEM, EDS spectroscopy was used. The photodegradation of dye solution against time and the reusability of the films were also monitored and studied.

\section{- EXPERIMENTAL SECTION}

\section{Materials}

Zinc oxide $(\mathrm{ZnO})$ and methylene blue dye was supplied by Fluka Co., silver nitrate from $\mathrm{BDH}$, polystyrene from local markets, acetone and chloroform by GCC, and were used without further purification. 


\section{Instrumentation}

UV VIS spectra were recorded for polystyrene, $\mathrm{ZnO} / \mathrm{PS}$ and $\mathrm{ZnO}-\mathrm{Ag} / \mathrm{PS}$ films in the range $200-800 \mathrm{~nm}$ using UV VIS spectrophotometer LF 4030, Scienco (Korea) by cutting pieces of the films $(2 \times 1) \mathrm{cm}$ and inserted in the UV VIS holder to record the spectra and blank holder was air. FTIR analysis is done directly for the films and tested using Affinity IR instrument (Shimadzu, Japan) recorded in the range $400-4000 \mathrm{~cm}^{-1}$, where the films located directly in the FTIR holder to record the spectra. XRD diffraction of $\mathrm{ZnO}$ and $\mathrm{ZnO}-\mathrm{Ag}$ are characterized by XRD apparatus (DX-2700 SSC, USA) using the films in the range $20-60^{\circ}$ of the diffraction angle (2theta). ZnO-Ag was analyzed by Scanning Electron Microscope Inspect 550, Netherland. EDS of ZnO-Ag was tested using energy dispersion X-ray (EDX), Bruker Nano $\mathrm{GmbH}$, Germany, where the powder is suspended in absolute ethanol, and the suspension dropped on a piece of aluminium for SEM and EDS analysis.

\section{Procedure}

\section{Preparation of composite of ZnO-Ag by photodeposition}

$\mathrm{ZnO}$ powder about $5 \mathrm{~g}$ was weighed and suspended in $100 \mathrm{~mL}$ of a mixture of distilled water/Acetone (50:50) with stirring for $1 \mathrm{~h}$. Silver nitrate was then added to the suspension, where the ratio of $\mathrm{Ag}$ was $2.5 \%$ molar ratio related to $\mathrm{ZnO}$ weight. The suspension was radiated using ultraviolet lamps (Phillips, $70 \mathrm{~W}$ ) for $4 \mathrm{~h}$, where this time all silver ion completely deposited on $\mathrm{ZnO}$ surface. $\mathrm{AgNO}_{3}$ was added to the filtrate of $\mathrm{ZnO}$ suspension to ensure no $\mathrm{AgCl}$ precipitate is formed. Finally, the white suspension turned into grey color and continuing until the maximum of the solvent is evaporating. $\mathrm{ZnO}-\mathrm{Ag}$ composite was then filtrated and washed with distilled water several times and dried at $80{ }^{\circ} \mathrm{C}$ for $12 \mathrm{~h}$. This sample is prepared for analysis like SEM and EDS.

\section{Preparation of ZnO-Ag/PS and ZnO/PS film}

Polystyrene $(0.95 \mathrm{~g})$ was dissolved in $20 \mathrm{~mL}$ of chloroform using magnetic stirrer for $3 \mathrm{~h}$ in reflux apparatus and followed by the addition of $0.05 \mathrm{~g}$ of $\mathrm{ZnO}$ or $\mathrm{ZnO}-\mathrm{Ag}$ with continuous stirring for $30 \mathrm{~min}$ to get a

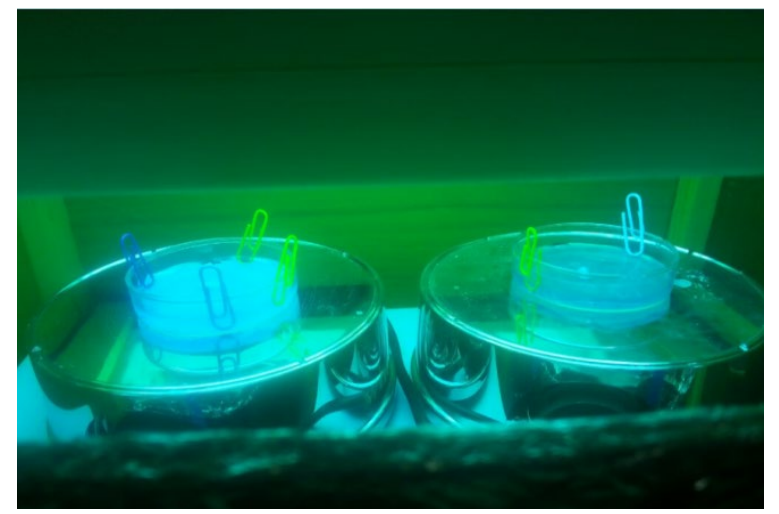

Fig 1. Photocatalytic degradation reaction installation (Petri dishes contain $\mathrm{ZnO} / \mathrm{PS}$ film on the left and $\mathrm{ZnO}$ $\mathrm{Ag} / \mathrm{PS}$ film on the right were immersed in $10 \mathrm{ppm}$ of methylene blue solution)

thick dispersed solution. After a slurry was formed, it was then poured in Petri dishes and left to evaporate in room temperature for $24 \mathrm{~h}$ to get casted films of $\mathrm{ZnO} / \mathrm{PS}$ and $\mathrm{ZnO}-\mathrm{Ag} / \mathrm{PS}$. The film without catalysts, which is polystyrene only, was used as a control film. These films are directly characterized by XRD, FTIR, and UV VIS spectroscopy.

\section{Photocatalytic degradation reaction}

Photocatalytic degradation ability of $\mathrm{ZnO}-\mathrm{Ag}$ and $\mathrm{ZnO}$ films was evaluated by the degradation of methylene blue under 70 watt UV lamp. In the degradation procedure, the film of $\mathrm{ZnO}-\mathrm{Ag} / \mathrm{PS}$, $\mathrm{ZnO} / \mathrm{PS}$, or PS were stacked in $5 \mathrm{~cm}$ diameter Petri dish reaching the base of the dish with metal buckle, keeping the film against floating and most of the solution will be above the film as shown in Fig. 1. Then $10 \mathrm{~mL}$ of methylene blue solution (10 ppm) was added with ensuring most of the solution is above the film; it was then stirred for $15 \mathrm{~min}$ in the dark until the adsorption/desorption equilibrium was reached. This is enough time for adsorption according to the amount of catalyst in the PS matrix, that is only $5 \% \mathrm{w} / \mathrm{w}$. The UV lamp was applied about $10 \mathrm{~cm}$ above the Petri dish, and the maximum absorbance of methylene blue was measured at $665 \mathrm{~nm}$ using UV-vis spectrophotometer scan between $200-800 \mathrm{~nm}$ wavelengths recorded every 15 min. 


\section{- RESULTS AND DISCUSSION}

$\mathrm{ZnO}-\mathrm{Ag} / \mathrm{PS}, \mathrm{ZnO} / \mathrm{PS}$, and PS films were characterized by FTIR analysis and appeared in Fig. 2. The common main peaks are the same with no shifting, except after catalyst mixing leads to strong absorption at $400-550 \mathrm{~cm}^{-1}$. Absorption bands at $3100 \mathrm{~cm}^{-1}$ belong to aromatic C-H stretching. The values of $2920 \mathrm{~cm}^{-1}$ and $2850 \mathrm{~cm}^{-1}$ absorption are assigned to $\mathrm{CH}_{2}$ group for the asymmetric and symmetric stretching vibrations respectively. Aromatic $\mathrm{C}=\mathrm{C}$ stretching peaks appeared at 1600 and $1500 \mathrm{~cm}^{-1}$. The $\mathrm{C}-\mathrm{H}$ deformation vibration band of benzene ring hydrogen appeared at $950 \mathrm{~cm}^{-1}$. Also, the mono-substituted ring showed absorption peaks at 759 and 654, while the main peak of $\mathrm{ZnO}$ in the $\mathrm{ZnO} / \mathrm{PS}$ composite was observed at the range $400-550 \mathrm{~cm}^{-1}$. When compared to this value with recent works of literature, it is similar to this work [23-24].

$\mathrm{UV}-\mathrm{V}$ is spectrum of $\mathrm{PS}, \mathrm{ZnO} / \mathrm{PS}$, and $\mathrm{ZnO}-\mathrm{Ag} / \mathrm{PS}$ are shown in Fig. 3, the PS does not show any appreciable absorption, and there is only a broad and less intense absorption band in the Vis region, while its absorption is $200-250 \mathrm{~nm}$. For the composite films, it can be seen that there is UV absorption in all the samples, in the range of 240-390 $\mathrm{nm}$, where the presence of zinc oxide enhances the UV absorption capacity of PS film. The $\mathrm{ZnO}$ content enhances the UV shielding properties of the polymer. When the number of dopant atoms increased, the gap of a semiconductor is lowered. Ag acts as a dopant that work as photo-sensitizer, which induce the separation of electron-hole pairs and prevent their recombination. Thus, the dopant works as a bridge to transfer charges between the localized stats [25]. Moreover, slight redshifts from 376 to $380 \mathrm{~nm}$ for the absorption peaks are observed in $\mathrm{ZnO}-\mathrm{Ag} / \mathrm{PS}$ film as a result of Ag doping. Such redshifts of the edge of absorption peaks of $\mathrm{ZnO}$ have also been reported [26].

$\mathrm{XRD}$ analysis was performed to analyze the degree of crystallinity and nature of $\mathrm{ZnO}$ and $\mathrm{ZnO}-\mathrm{Ag}$ composites, with $\mathrm{CuKa}$ radiation $(40 \mathrm{Kv}, 30 \mathrm{~mA})$. The diffraction of X-ray showed spectra of $\mathrm{ZnO} / \mathrm{PS}$ and

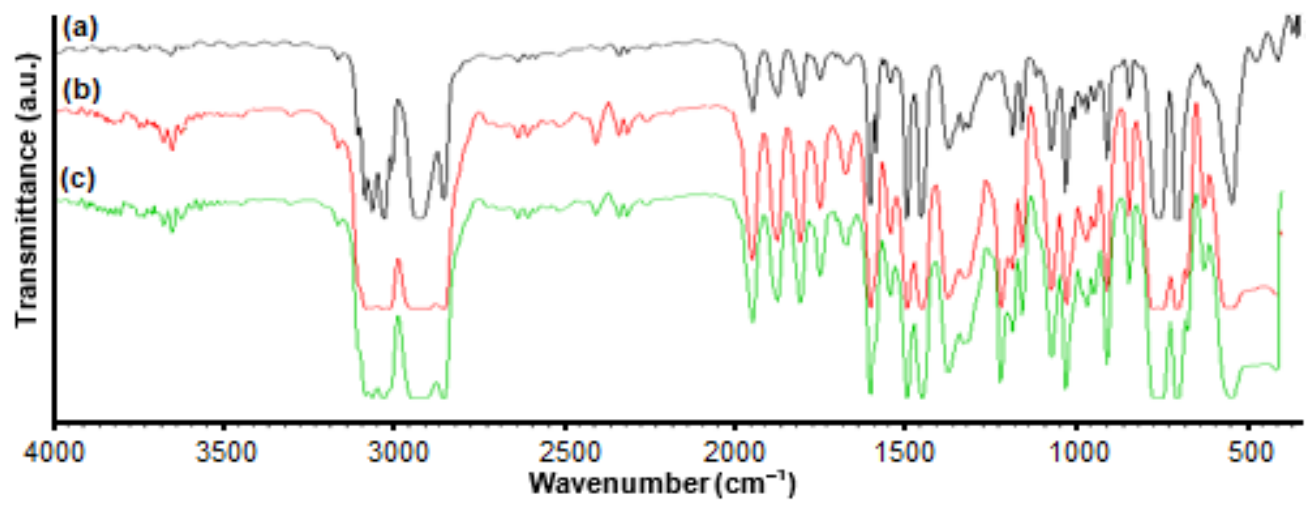

Fig 2. The FTIR spectra of (a) polystyrene films, (b) $\mathrm{ZnO} / \mathrm{PS}$ films, and (c) $\mathrm{ZnO}-\mathrm{Ag} / \mathrm{PS}$ films

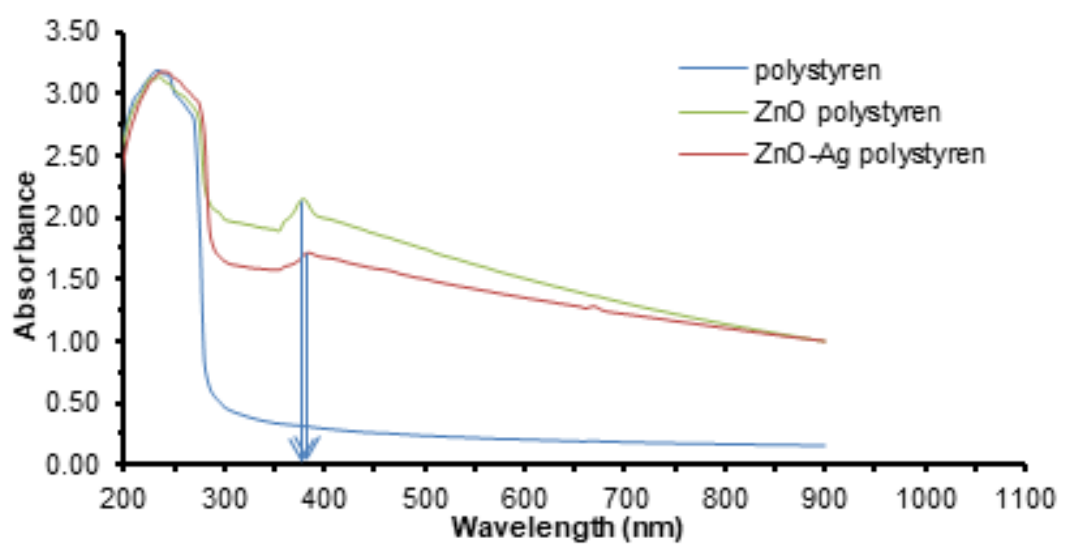

Fig 3. UV VIS spectra of $\mathrm{PS}, \mathrm{ZnO} / \mathrm{PS}$, and $\mathrm{ZnO}-\mathrm{Ag} / \mathrm{PS}$ 
$\mathrm{ZnO}-\mathrm{Ag} / \mathrm{PS}$ composites. Characteristic peaks appeared in the range of $2 \theta$ values of $20-60^{\circ}$, where the presence of several peaks indicating that the crystallinity of the composite is high, as shown in Fig. 4.

According to Fig. 4, $\mathrm{ZnO}-\mathrm{Ag}$ peaks indicating the presence of silver and $\mathrm{ZnO}$ phases and no other structure is formed after doping. This means $\mathrm{ZnO}$ and $\mathrm{Ag}$ metal are the only phases that are found after photodeposition with successive reduction of $\mathrm{Ag}$ ion on to $\mathrm{ZnO}$ surface. XRD data for all studied samples are observed that the essential peaks occur at Miller indexes (100), (002), (101), (102), and (110), where the diffraction peaks are $31.80,34.41$, $36.21,47.52$, and 56.53. The main peaks of $\mathrm{ZnO}$ are similar to the $\mathrm{ZnO}$ phase liked wurtzite (hexagonal) structure, according to JCPDS card no. 36-1451. The new peak at $38.05^{\circ}$ in $\mathrm{ZnO}-\mathrm{Ag} / \mathrm{PS}$ spectra does not belong to $\mathrm{ZnO}$, but it is an indication of the presence of a silver particle in the (111) crystal plane that rapped on $\mathrm{ZnO}$ surface. As the amount of Ag is low, the x-ray will not be sensitive to all diffracted peaks like 44.38 angle, thus (200) crystal planes of silver would not appear in the spectra [27].

$\mathrm{ZnO}-\mathrm{Ag}$ composite was analyzed by SEM instrument to show the morphology of this photocatalyst and showed highly roughness, and the particles are distributed as dimensional form, which gives a good feature in surface area. Fig. 5(a) shows the SEM image of $\mathrm{ZnO}-\mathrm{Ag}$ composite, and Fig. 5(b) is the EDS analysis of $\mathrm{ZnO}-\mathrm{Ag}$, and according to this test, the composite contained $\mathrm{Zn}, \mathrm{O}$, and Ag only. The presence of Ag peak indicates the successful modification of $\mathrm{ZnO}$ by Ag using photodeposition method. EDS analysis showed the atomic percentage that the amount of silver deposit on $\mathrm{ZnO}$ was $2 \%$, while the percentage of $\mathrm{Ag}$ in the solution to prepare $\mathrm{ZnO}-\mathrm{Ag}$ was $2.5 \%$ and this is a good result, where the error was low.

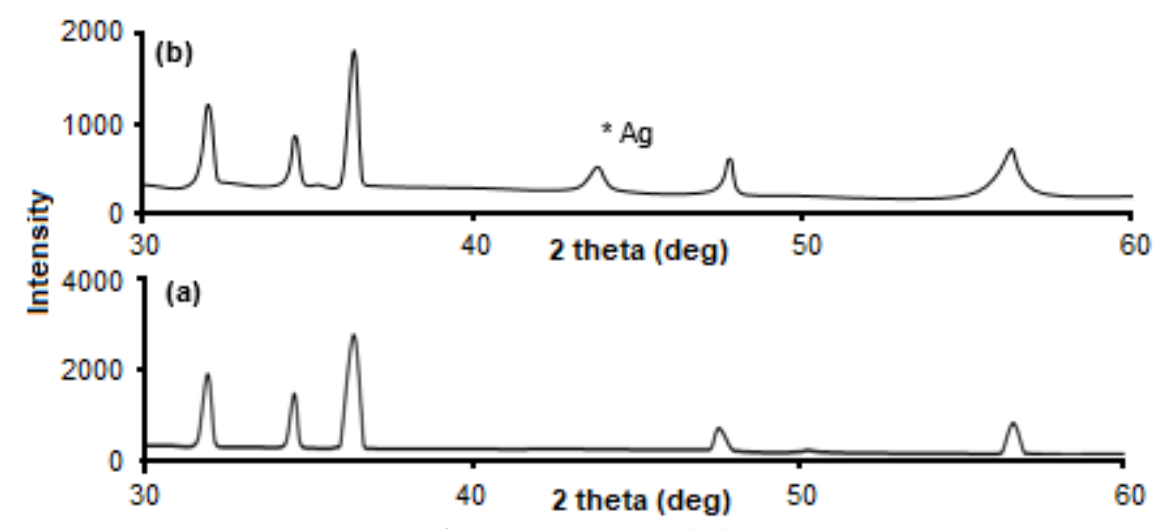

Fig 4. $\mathrm{XRD}$ of (a) $\mathrm{ZnO} / \mathrm{PS}$ and (b) $\mathrm{ZnO}-\mathrm{Ag} / \mathrm{PS}$
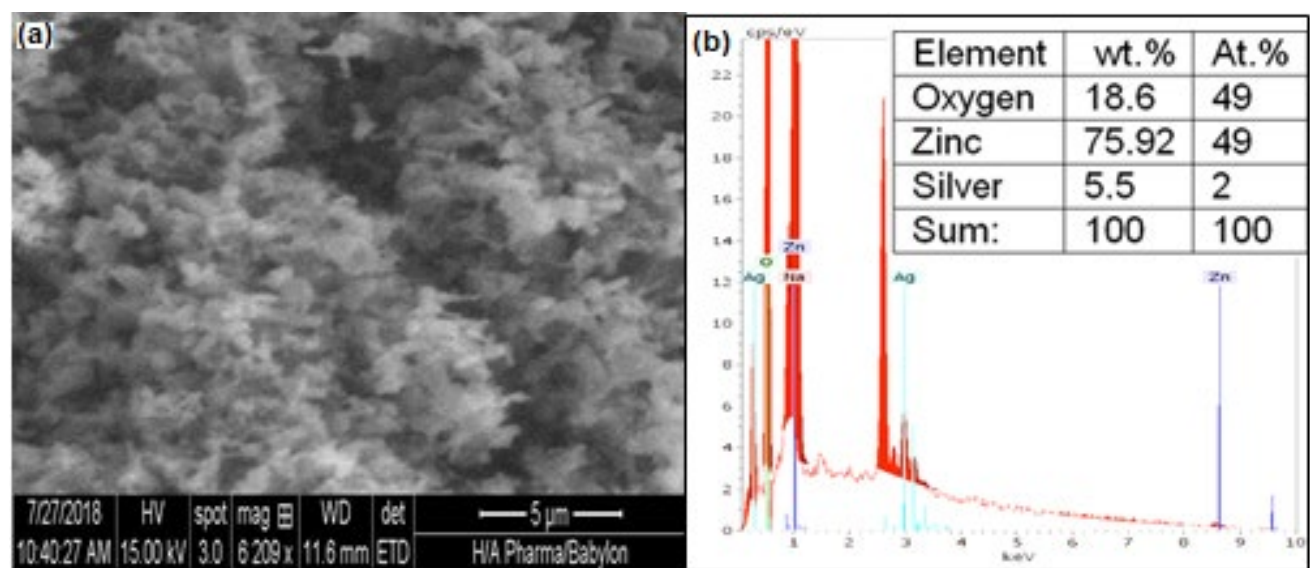

Fig 5. (a) SEM image and (b) EDS analysis of $\mathrm{ZnO}-\mathrm{Ag}$ (the inserted table is weight and atomic elements percentage of $\mathrm{ZnO}-\mathrm{Ag})$ 
Photocatalytic degradation activity of $\mathrm{ZnO} / \mathrm{PS}$ and $\mathrm{ZnO}-\mathrm{Ag} / \mathrm{PS}$ were studied by degrading of $\mathrm{MB}$ dye under UV-irradiation in comparison to PS film. MB dye has maximum absorption at $665 \mathrm{~nm}$, and the absorption is monitored to evaluate the photodegradation of $\mathrm{MB}$, where in case of PS film there is a slight change in MB absorption, and this indicates the PS film has poor photocatalytic degradation.

In the case of $\mathrm{ZnO}-\mathrm{Ag} / \mathrm{PS}$ and $\mathrm{ZnO} / \mathrm{PS}$ films, $\mathrm{MB}$ absorption is decreased with time due to the vanishing color by photocatalytic reaction, and this decreasing is continuing until the color of MB is disappeared. Fig. 6 shows the UV VIS spectra of MB solution with a concentration of $10 \mathrm{ppm}$ in the presence of UV irradiation with proceeding time. In Fig. 6(a), the photodegradation of $\mathrm{MB}$ is very low as there is no photocatalyst, where PS film without catalyst, and the MB absorption was slightly changed related to initial concentration. Fig. 6(b) represents the effect of $\mathrm{MB}$ photodegradation by $\mathrm{ZnO} / \mathrm{PS}$ film, and it can be seen that the absorption of $\mathrm{MB}$ is changing in time proceeding. This also revealed that $\mathrm{MB}$ degraded by the action of $\mathrm{ZnO} / \mathrm{PS}$ film is a good method to eliminate the dyes from industrial textile effluent. The degradation of $\mathrm{MB}$ solution using $\mathrm{ZnO}-\mathrm{Ag} / \mathrm{PS}$ catalyst is shown in Fig. 6(c); $\mathrm{MB}$ was more degradable in the same conditions in comparison with $\mathrm{ZnO}-\mathrm{Ag} / \mathrm{PS}$ and PS films. According to this result, the degradation activity will be more efficient as much as exposing to UV irradiation. Finally, the color tends to be colorless of $\mathrm{MB}$ as the full destruction of chemical structure.

PS as a polymer has low degradation activity and this regards to wide bandgap; therefore, it did not show any degradation of $\mathrm{MB}$ solution. $\mathrm{ZnO}-\mathrm{Ag} / \mathrm{PS}$ was more effective in $\mathrm{MB}$ removal than $\mathrm{ZnO} / \mathrm{PS}$ film, and this attributed to the Ag doping. This modification changed the surface nature and made new active sites, increasing the surface area. Also, the photocatalytic activity of $\mathrm{ZnO}$ $\mathrm{Ag} / \mathrm{PS}$ was enhanced due to metallic Ag deposition on the surface of $\mathrm{ZnO}$, and this metal works as electrons

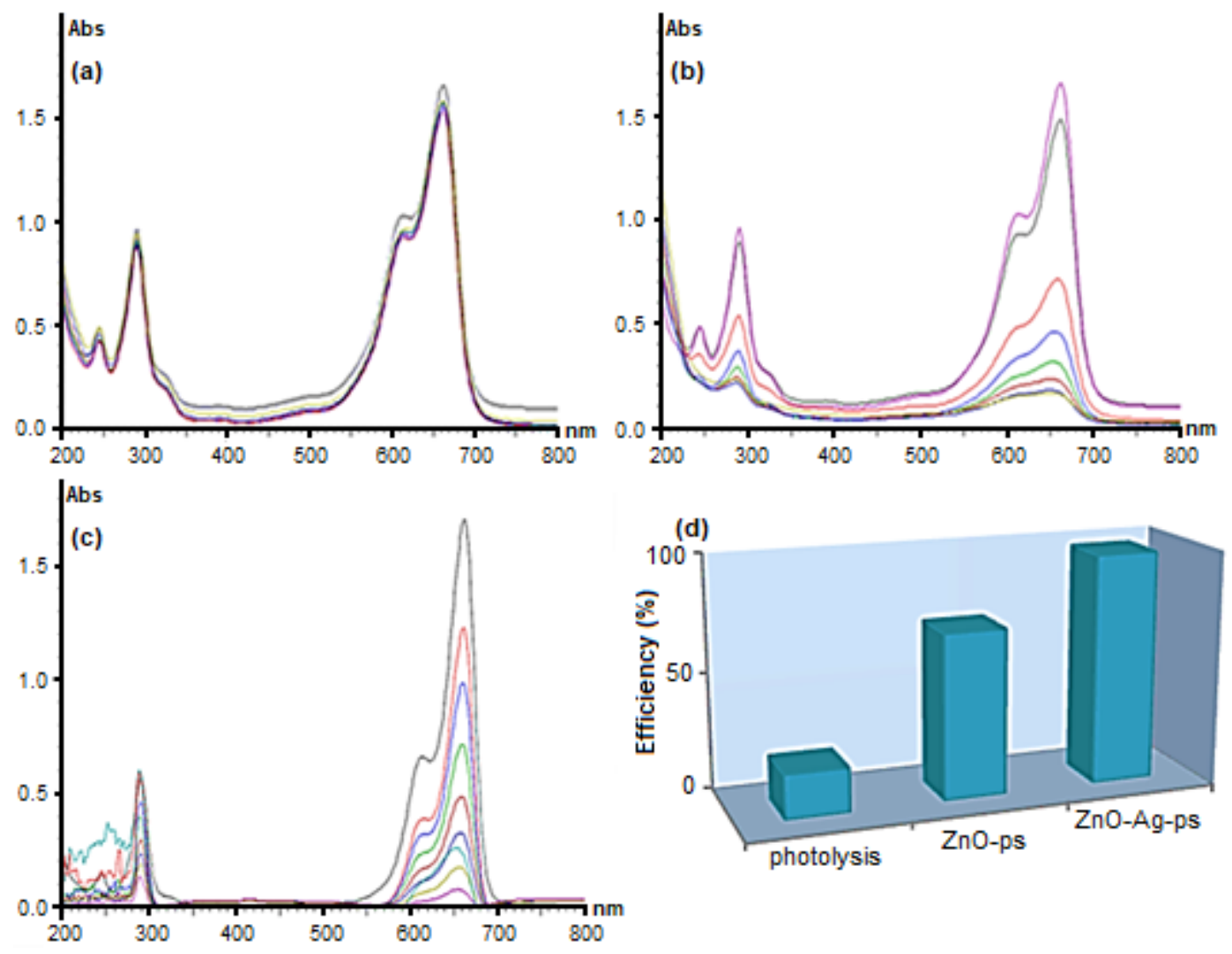

Fig 6. Photodegradation of $\mathrm{MB}$ by (a) PS film, (b) $\mathrm{ZnO} / \mathrm{PS}$ film, (c) $\mathrm{ZnO}-\mathrm{Ag} / \mathrm{PS}$ film, and (d) efficiency of photodegradation of the three films 
collectors. Silver nanoparticles that trapped on $\mathrm{ZnO}$ surface modify the surface with new geometrical active sites. This modification leads to change the electronic properties and increase the separation time of the electron-hole pair to give more time for electron trapping. Electrons trapped tend to move to an oxidized agent like the adsorbed molecular oxygen, and this prevents the recombination of electron-hole pairs. Thus the degradation efficiency was increased [28-29].

In addition, the $\mathrm{ZnO}-\mathrm{Ag} / \mathrm{PS}$ ability in $\mathrm{MB}$ degradation result from the electron-hole could have more than one pathway for the formation of electron-hole with more time and forbidding recombination as the three different interfaces of $\mathrm{ZnO}-\mathrm{Ag}$ composite. The comparison of the photodegradation efficiency of the three films is shown in Fig. 6(d), where high efficiency of $\mathrm{ZnO}-\mathrm{Ag} / \mathrm{ps}$ film in the same conditions is reached up to 97\% for $120 \mathrm{~min}$ after reaction, while $\mathrm{ZnO} / \mathrm{ps}$ was $70 \%$ and PS film alone was $19 \%$ and this result is similar as reported [30].

The photocatalytic reaction of films against $\mathrm{MB}$ removal kinetics was studied, and it found that this kind of reaction follows pseudo-first-order kinetics. The most mechanism that fallow this reaction is a LangmuirHinshelwood mechanism. This mechanism can explain the degradation activity of heterogeneous photocatalyst. Depending on the concentration of $\mathrm{MB}$ dye, when the concentration of $\mathrm{MB}$ dye is low, the rate expression can be written as $\mathrm{d}[\mathrm{C}] / \mathrm{dt}=\mathrm{k}[\mathrm{C}]$. $\mathrm{k}$ is the apparent constant of first-order rate calculated by the linear regression of the equation the $\mathrm{k}=\ln \left(\mathrm{C}_{\mathrm{MBo}} / \mathrm{C}_{\mathrm{MB}}\right) / \mathrm{t}$, where $\mathrm{C}_{\mathrm{oMB}}$ and $\mathrm{C}_{\mathrm{MB}}$ are the concentrations of $\mathrm{MB}$ dyes at the irradiation time 0 and $t \mathrm{~min}$, respectively. Plots of $\ln \left(\mathrm{C} / \mathrm{C}_{\mathrm{o}}\right)$ against the time of irradiation gives a straight line, as shown in Fig. 7 , and the slope of the linear fitted line represents the value of $\mathrm{k}$. The calculated $\mathrm{k}$ values were equal to 0.0284 , 0.0253 , and $0.0007 \mathrm{~min}^{-1}$ for $\mathrm{ZnO}-\mathrm{Ag} / \mathrm{PS}, \mathrm{ZnO} / \mathrm{PS}$, and PS films, respectively. It is obvious that $\mathrm{ZnO}-\mathrm{Ag} / \mathrm{PS}$ has a high degradation rate of $\mathrm{MB}$ dye under UV irradiation. According to these results, $\mathrm{ZnO}-\mathrm{Ag} / \mathrm{PS}$ can be used as treatment techniques to eliminate pollution by dyes through effluent wastewater [31-33].

The efficiency of MB photodegradation is clearly obvious in the presence of the photocatalyst $\mathrm{ZnO} / \mathrm{PS}$ and $\mathrm{ZnO}-\mathrm{Ag} / \mathrm{PS}$ and PS. However, the amount of catalysts in the matrix in polystyrene film is low. $\mathrm{ZnO} / \mathrm{PS}$ and $\mathrm{ZnO}$ $\mathrm{Ag} / \mathrm{PS}$ were highly active to diminish the color of $\mathrm{MB}$, where $\mathrm{ZnO}-\mathrm{Ag} / \mathrm{PS}$ was very efficient as a result of a combination of $\mathrm{Ag}$ on $\mathrm{ZnO}$ surface. Fig. 8 shows the efficiency of photodegradation by UV light only, and the

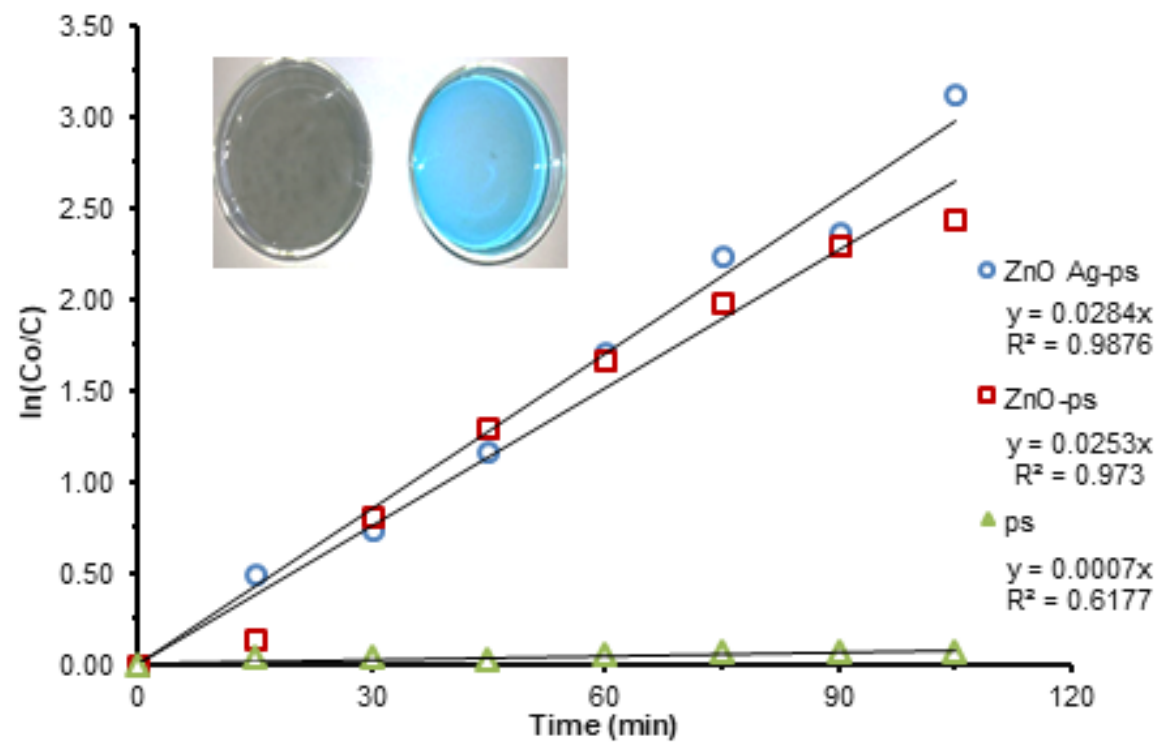

Fig 7. The first order plot of MB photodegradation (a) PS film, (b) $\mathrm{ZnO} / \mathrm{Ag}$ film, (c) $\mathrm{ZnO}-\mathrm{Ag} / \mathrm{PS}$ film. The insight picture is Petri dishes of MB solution without catalyst on the right and with $\mathrm{ZnO}-\mathrm{Ag} / \mathrm{PS}$ film on the left at the end of the reaction 


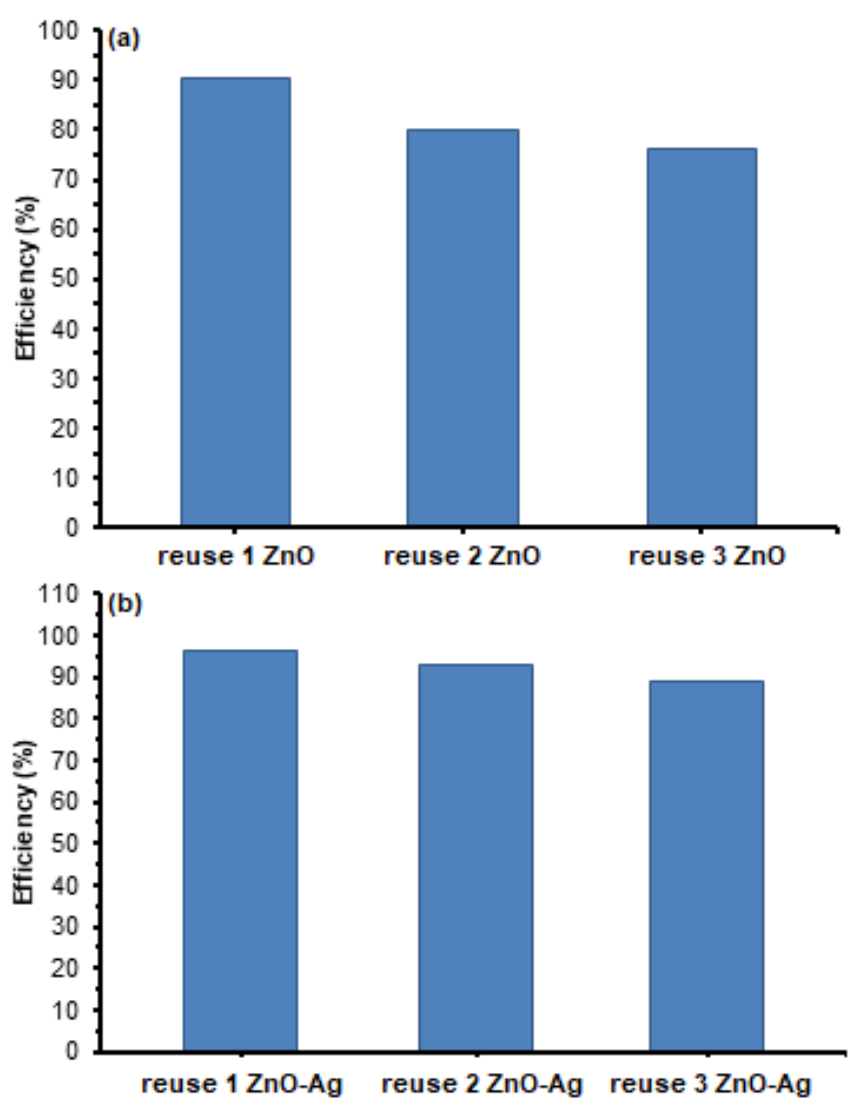

Fig 8. Photodegradation efficiency after reusing the (a) $\mathrm{ZnO} / \mathrm{PS}$ and (b) $\mathrm{ZnO}-\mathrm{Ag} / \mathrm{PS}$ films

catalyst of $\mathrm{ZnO} / \mathrm{PS}$ and $\mathrm{ZnO}-\mathrm{Ag} / \mathrm{PS}$ efficiency, which was 20,80 , and $96 \%$, respectively. Another aspect of this study was testing the photodegradation activity after several runs, reusing the film again to ensure that the films can be used several times and measuring their efficiency in the degradation of MB. This experiment was accomplished by decanting the solution of $\mathrm{MB}$ after decolorization and replaced by a new solution of $\mathrm{MB}$ and illuminated by UV light, and the absorbance was measured so that the efficiency is calculated. Fig. 8 shows the efficiency of $\mathrm{ZnO} / \mathrm{PS}$ and $\mathrm{ZnO}-\mathrm{Ag} / \mathrm{PS}$ films after were used in the first photodegradation and reused three times. $\mathrm{ZnO} / \mathrm{PS}$ and $\mathrm{ZnO}-\mathrm{Ag} / \mathrm{PA}$ films have good reusability of photodegradation efficiency. The reusability of the catalysts is a benefit for cost-effectiveness to reduce the consumption of catalyst films each photodegradation process as reported [34-35].

\section{- CONCLUSION}

$\mathrm{ZnO}$ and $\mathrm{ZnO}-\mathrm{Ag}$ stabilized in polystyrene matrix give high efficiency in photocatalytic degradation of $\mathrm{MB}$ and had good reusability. Photodepositon of $\mathrm{Ag}$ on $\mathrm{ZnO}$ surface made a surface modification, according to the analysis of XRD, SEM, and EDS, making the MB degradation using $\mathrm{ZnO}-\mathrm{Ag} / \mathrm{PS}$ film was higher than using $\mathrm{ZnO} / \mathrm{PS}$ film. In the same period of $\mathrm{MB}$ degradation, $\mathrm{ZnO}-\mathrm{Ag} / \mathrm{PS}$ efficiency was $97 \%$, while it was $70 \%$ for $\mathrm{ZnO} / \mathrm{PS}$ film. $\mathrm{ZnO}-\mathrm{Ag} / \mathrm{PS}$ film can be reused three times with the efficiency reached $89 \%$ compared to $\mathrm{ZnO} / \mathrm{PS}$ film, which was $76 \%$.

\section{- REFERENCES}

[1] Sangpour, P., Hashemi, F., and Moshfegh, A.Z., 2010, Photoenhanced degradation of methylene blue on cosputtered $\mathrm{M}: \mathrm{TiO}_{2}(\mathrm{M}=\mathrm{Au}, \mathrm{Ag}, \mathrm{Cu})$ nanocomposite systems: A comparative study, J. Phys. Chem. C, 114 (33), 13955-13961.

[2] Li, D., Zhang, Y., Wu, W., and Pan, C., 2014, Preparation of a $\mathrm{ZnO} / \mathrm{TiO}_{2}$ vertical-nanoneedleon-film heterojunction and its photocatalytic properties, RSC Adv., 4 (35), 18186-18192.

[3] Teh, C.M., and Mohamed, A.R., 2011, Roles of titanium dioxide and ion-doped titanium dioxide on photocatalytic degradation of organic pollutants (phenolic compounds and dyes) in aqueous solutions: A review, J. Alloys Compd., 509 (5), 16481660.

[4] Josephine, G.S., and Sivasamy, A., 2014, Nanocrystalline $\mathrm{ZnO}$ doped on lanthanide oxide $\mathrm{Dy}_{2} \mathrm{O}_{3}$ : A novel and UV light active photocatalyst for environmental remediation, Environ. Sci. Technol. Lett., 1 (2), 172-178.

[5] Zhao, H., Deng, W., and Li, Y., 2018, Atomic layer deposited $\mathrm{TiO}_{2}$ ultrathin layer on Ag_ZnO nanorods for stable and efficient photocatalytic degradation of RhB, Adv. Compos. Hybrid Mater., 1 (2), 404-413.

[6] Ahmed, S., Rasul, M.G., Martens, W.N., Brown, R., and Hashib, M.A., 2010, Heterogeneous 
photocatalytic degradation of phenols in wastewater: A review on current status and developments, Desalination, 261 (1-2), 3-18.

[7] Zheng, Y., Chen, C., Zhan, Y., Lin, X., Zheng, Q., Wei, K., and Zhu, J., 2008, Photocatalytic activity of $\mathrm{Ag} / \mathrm{ZnO}$ heterostructure nanocatalyst: Correlation between structure and property, J. Phys. Chem. C, 112 (29), 10773-10777.

[8] Sapkota, A., Anceno, A.J., Baruah, S., Shipin, O.V., and Dutta, J., 2011, Zinc oxide nanorod mediated visible light photoinactivation of model microbes in water, Nanotechnololy, 22 (21), 215703.

[9] Khodja, A.A., Sehili, T., Pilichowski, J.F., and Boule, P., 2001, Photocatalytic degradation of 2phenylphenol on $\mathrm{TiO}_{2}$ and $\mathrm{ZnO}$ in aqueous suspensions, J. Photochem. Photobiol., A, 141 (2-3), 231-239.

[10] Chakrabarti, S., Chaudhuri, B., Bhattacharjee, S., Das, P., and Dutta, B.K., 2008, Degradation mechanism and kinetic model for photocatalytic oxidation of PVC- $\mathrm{ZnO}$ composite film in presence of a sensitizing dye and UV radiation, J. Hazard. Mater., 154 (1-3), 230-236.

[11] Sridharan, K., Jang, E., Park, Y.M., and Park, T.J., 2015, Superior photostability and photocatalytic activity of $\mathrm{ZnO}$ nanoparticles coated with ultrathin $\mathrm{TiO}_{2}$ layers through atomic-layer deposition, Chem. Eur. J., 21 (52), 19136-19141.

[12] Fan, Y., Han, D., Song, Z., Sun, Z., Dong, X., and Niu, L., 2017, Regulations of silver halide nanostructure and composites on photocatalysis, Adv. Compos. Hybrid Mater., 1 (2), 269-299.

[13] Pareek, V.K., and Adesina, A.A., 2004, Light intensity distribution in a photocatalytic reactor using finite volume, AlChE J., 50 (6), 1273-1288.

[14] Pouretedal, H.R., Norozi, A., Keshavarz, M.H., and Semnani, A., 2009, Nanoparticles of zinc sulfide doped with manganese, nickel and copper as nanophotocatalyst in the degradation of organic dyes, J. Hazard. Mater., 162 (2-3), 674-681.

[15] Rauf, M.A., Meetani, M.A., Khaleel, A., and Ahmed, A., 2010, Photocatalytic degradation of methylene blue using a mixed catalyst and product analysis by LC/MS, Chem. Eng. J., 157 (2-3), 373-378.

[16] Oda, A.M., Ferhod, A.S., and Lafta, A.J., 2014, Modification of the photocatalytic activity of zinc oxide by doping silver, IJSR, 3 (11), 2133-2139.

[17] Oda, A.M., Ali, H.H., Lafta, A.J., Esmael, H.A., Jameel, A.A., Mohammed, A.M., and Mubarak, I.J., 2015, Study self-cleaning of Congo red from cotton fabric loaded by ZnO-Ag, Int. J. Chem., 7 (2), 39-48.

[18] Oda, A.M., Khuder, H., Hashim, R., Rasheed, A., Hasan, A.A., Hazim, H., and Raheem, Z., 2016, Photocatalytic degradation of safranin $\mathrm{O}$ by $\mathrm{ZnO}$ Ag loaded on cotton fabric, Res. J. Pharm. Biol. Chem. Sci., 7 (5), 2915-2924.

[19] Singh, S., Singh, P.K., and Mahalingam, H., 2014, Novel floating $\mathrm{Ag}^{+}$-doped $\mathrm{TiO}_{2} /$ polystyrene photocatalysts for the treatment of dye wastewater, Ind. Eng. Chem. Res., 53 (42), 16332-16340.

[20] Zandsalimi, Y., Teymouri, P., Soltani, R.D.C., Rezaee, R., Abdullahi, N., and Safari, M., 2015, Photocatalytic removal of Acid Red 88 dye using zinc oxide nanoparticles fixed on glass plates, $J$. Adv. Environ. Health Res., 3 (2), 102-110.

[21] Di Mauro, A., Cantarella, M., Nicotra, G., Pellegrino, G., Gulino, A., Brundo, M.V. Privitera, V., and Impellizzeri, G., 2017, Novel synthesis of $\mathrm{ZnO} / \mathrm{PMMA}$ nanocomposites for photocatalytic applications, Sci. Rep., 7, 40895.

[22] Kunarti, E.S., Kartini, I., Syoufian, A., and Widyandari, K.M., 2018, Synthesis and photoactivity of $\mathrm{Fe}_{3} \mathrm{O}_{4} / \mathrm{TiO}_{2}$-Co as a magnetically separable visible light responsive photocatalyst, Indones. J. Chem., 18 (3), 403-410.

[23] Chae, D.W., and Kim, B.C., 2005, Characterization on polystyrene/zinc oxide nanocomposites prepared from solution mixing, Polym. $A d v$. Technol., 16 (11-12), 846-850.

[24] Kaniappan, K., and Latha, S., 2011, Certain investigations on the formulation and characterization of polystyrene/poly(methyl methacrylate) blends, Int. J. ChemTech Res., 3 (2), 708-717. 
[25] Sangawar, V.S., and Golchha, M.C., 2013, Evolution of the optical properties of polystyrene thin films filled with zinc oxide nanoparticles, Int. J. Sci. Eng. Res., 4 (6), 2700-2705.

[26] Zhou, X.D., Xiao, X.H., Xu, J.X., Cai, G.X., Ren, F., and Jiang, C.Z., 2011, Mechanism of the enhancement and quenching of $\mathrm{ZnO}$ photoluminescence by $\mathrm{ZnO}$ Ag coupling, Europhys. Lett., 93 (5), 57009.

[27] Aazam E.S., 2014, Visible light photocatalytic degradation of thiophene using $\mathrm{Ag}-\mathrm{TiO}_{2} /$ multiwalled carbon nanotubes nanocomposite, Ceram. Int., 40 (5), 6705-6711.

[28] Ren, C., Yang, B., Wu, M., Xu, J., Fu, Z., lv, Y., Guo, T., Zhao, Y., and Zhu, C., 2010, Synthesis of Ag/ZnO nanorods array with enhanced photocatalytic performance, J. Hazard. Mater., 182 (1-3), 123-129.

[29] Subash, B., Krishnakumar, B., Swaminathan, M., and Shanthi, M., 2013, Highly efficient, solar active, and reusable photocatalyst: $\mathrm{Zr}$-loaded $\mathrm{Ag}-\mathrm{ZnO}$ for reactive red 120 dye degradation with synergistic effect and dye-sensitized mechanism, Langmuir, 29 (3), 939-949.

[30] Fageria, P., Gangopadhyay, S., and Pande, S., 2014, Synthesis of $\mathrm{ZnO} / \mathrm{Au}$ and $\mathrm{ZnO} / \mathrm{Ag}$ nanoparticles and their photocatalytic application using UV and visible light, RSC Adv., 4 (48), 24962-24972.
[31] Saravanan, R., Khan, M.M., Gupta, V.K., Mosquera, E., Gracia, F., Narayanan, V., and Stephen, A., 2015, $\mathrm{ZnO} / \mathrm{Ag} / \mathrm{Mn}_{2} \mathrm{O}_{3}$ nanocomposite for visible lightinduced industrial textile effluent degradation, uric acid and ascorbic acid sensing and antimicrobial activity, RSC Adv., 5 (44), 34645-34651.

[32] Byrappa, K., Subramani, A.K., Ananda, S., Rai, K.M.L., Dinesh, R., and Yoshimura, M., 2006, Photocatalytic degradation of rhodamine $\mathrm{B}$ dye using hydrothermally synthesized $\mathrm{ZnO}$, Bull. Mater. Sci., 29 (5), 433-438.

[33] Patchaiyappan, A., Saran, S., and Devipriya, S.P., 2016, Recovery and reuse of $\mathrm{TiO}_{2}$ photocatalyst from aqueous suspension using plant based coagulant-A green approach, Korean J. Chem. Eng., 33 (7), 2107-2113.

[34] Krishnakumar, B., Subash, B., and Swaminathan, M., 2012, AgBr-ZnO-An efficient nanophotocatalyst for the mineralization of acid black 1 with UV light, Sep. Purif. Technol., 85, 35-44.

[35] Saravanan, R., Khan, M.M., Gupta, V.K., Mosquera, E., Gracia, F., Narayanan, V., and Stephen, A., 2015, $\mathrm{ZnO} / \mathrm{Ag} / \mathrm{CdO}$ nanocomposite for visible lightinduced photocatalytic degradation of industrial textile effluents, J. Colloid Interface Sci., 452, 126133. 